\title{
A Sociology of Teaching, Learning and Enhancement: improving practices in higher education
}

\author{
Paul R. Trowler \\ Lancaster University. Department of Educational Research \\ United Kingdom \\ p.trowler@lancaster.ac.uk
}

\begin{abstract}
This paper examines the relative lack of attention given to learning and teaching issues at the departmental level in universities. Using a social practice theory approach, the paper shows how the construction and enactment of teaching and learning regimes at the departmental level can have significant effects on the reception and implementation of intiatives designed to enhance practices and outcomes associated with teaching and learning in university contexts.
\end{abstract}

Key words: sociology, teaching and learning, higher education, social practice, cultures, regimes.

Resum. Una sociologia de l'ensenyament i l'aprenentatge: millorant les pràctiques a l'educació superior

Aquest article examina la falta relativa d'atenció sobre les qüestions d'ensenyament i aprenentatge en el nivell departamental de les universitats. Utilitzant la teoria de la pràctica social com a aproximació al tema, l'article mostra com la construcció i la posada en funcionament dels règims d'ensenyament $\mathrm{i}$ aprenentatge a nivell departamental pot tenir efectes significatius sobre la recepció i la implementació d'iniciatives dissenyades per millorar les pràctiques i els resultats de l'aprenentatge i l'ensenyament en contextos universitaris.

Paraules clau: sociologia, ensenyament i aprenentatge, educació superior, pràctica social, cultures, règims.

\section{Summary}

The Sociology of Education

The missing meso level

Lacunae

A sociology of teaching and learning

Theoretical precursors

A sociology of enhancement
Policies and practices

Teaching and Learning Regimes and the Enhancement of Practices

Implications for enhancement

A final comment

References 


\section{The Sociology of Education}

\section{The focus}

The sociology of education is a well developed area of research, at least in the United Kingdom. Its main focus of attention has traditionally been on the structured character of underachievement in our schools. In its early years, from the $1950 \mathrm{~s}$, it focused on the ways in which social class background structured the educational experience and life chances of people. Later, in the 1970s and early 80 s, the focus shifted to gender as the significant structuring factor. Later still the focus shifted to ethnicity and then, most recently, to disability.

\section{Explanatory theories}

Meanwhile there has been a shift in the type of theory employed to explain these structured inequalities. In the early days the focus was on material deprivation: on inadequate housing, physical circumstances, poor nutrition, lack of resources, consequent illness and a consequent inability to give priority to education. Later, differences in culture were thought to be significant; in the use of language, parental attitudes towards education and the different aspirations of the social classes. In the 1970s interactionist theory took hold and classroom processes between individual teachers and pupils - rooted in social class, gender and ethnic stereotyping - became seen as significant contributory factors in explaining underachievement among these groups. Shortly afterwards the «new» sociology of knowledge began to look not at the children, parents or teachers but at the nature of the school curriculum, at privileged forms of knowledge, and to ask who had access to them and who was denied such access.

\section{The level of analysis}

For sociologists of education «class» has almost always meant primarily social class, not class as in classroom. This points us to the distinctive characteristic of the sociology of education: its level of analysis at the macro, societal, scale. The sociology of education has been a sociology of educational systems, of the interaction between economy, culture and society (to steal the subtitle of a classic text in the area: Halsey et al., 1997) on the one hand and educational provision on the other. The main exception to this was the foray into interactionism in the early and mid 1970s, but there still the interaction was seen as largely conditioned by wider social forces and its outcomes were believed to replicate on the small scale structured inequalities on the wider scale.

Thus the «sociology of education» is actually code for a macro perspective on educational issues. As Whitty $(2002,14)$ says:

A graphic, though perhaps unfortunate, metaphor for the role of sociology in educational studies might be a «vulture's eye view» of the world. Apparently 
a vulture is always able to keep the background landscape in view while enlarging its object of immediate interest.

This perspective continues today. A scan of the chapter on education of a recent sociology textbook for matriculation and first-year degree (Haralambos and Holborn, 2004) shows a focus on: sociological and political perspectives on education at the system level; the history of the education system; New Labour and Post-Fordist perspectives on education and the economy; postmodern perspectives; evidence and explanations concerning differential educational achievement by social classes; the interactionist perspective on education; gender and ethnicity and educational attainment.

The sociology of higher education has remained restricted to much the same territory: though much less of it is covered, and largely at a more restricted theoretical level. Thus for example Tight's thorough analysis of research output in the field of higher education (2003) shows that there are considerably fewer theoretically grounded studies than is the case in the study of compulsory education.

\section{The missing meso level}

All this is not to say of course that teaching and learning ${ }^{1}$ remains unstudied, nor that the micro level of analysis is ignored. But it is psychology, rather than sociology, that has predominantly claimed this ground to date.

In the field of teaching and learning in higher education there has been a considerable amount of attention paid to issues such as:

- Deep and surface learning.

- Conceptions of learning.

- Conceptions of teaching.

- Teacher thinking, beliefs and knowledge.

Thus a textbook designed for higher education practitioners (Biggs, 1999) covers such concepts in considerable detail. However these have predominantly restricted attention to individual cognition, seeing the individual, their conceptions, approaches and practices as largely independent of their context, or at least paying only limited attention to the interaction between figure and ground. Much of this comes out of phenomenographic research — an approach which has taken hold most fully in HE research and seeks to explore the range of conceptions held about teaching and learning among a population of individuals. Trigwell defines phenomenography thus:

Phenomenography is the empirical study of the limited number of qualitatively different ways in which we experience, conceptualise, understand, per-

1. "Teaching and learning» is here used as shorthand for teaching, learning, assessment and curriculum. This is wider territory but more cumbersome to express. 
ceive, apprehend etc, various phenomena in and aspects of the world around us. [...] Reality is not seen as being «out there». It is seen as being constituted as the relation between the individual and the phenomenon. (Trigwell, 2000)

The «we» here is clearly meant to refer to individuals aggregated together rather than in social context, as is made clear by the reference to reality being constituted by the relation between the individual and the phenomenon.

Underpinning such psychologically-based approaches is the question "how can the processes of teaching and learning be enhanced?». As we will see below, while this is a very good question, it is not the only possible one.

\section{Lacunae}

What is missing here is an understanding of teaching and learning in their social contexts, of the figure situated in their particular ground. The missing level of analysis is the meso level — the point of social interaction by small groups such as exist in the classroom, in the university department, in the curriculum-planning team or in a hundred other task-based teams within the higher educational system.

The lacuna, in short, is a social theory of learning, illuminated by sociology, as well as a theory of cognition illuminated by psychology. Coffield expresses the distinction succinctly in his discussion of the absence of elaborated social theories of learning:

[...] a social theory of learning argues that learning is located in social participation and dialogue as well as in the heads of individuals; and it shifts the focus from a concentration on individual cognitive processes to the social arrangements and relationships which shape, for instance, positive and negative «learner identities» which may differ over time and from place to place. (Coffield, 1999, 493. Emphasis mine)

There are elements of such theory in place at the moment, but they are rarely applied to teaching and learning in general and particularly not to that dimension of higher education. Neither do they yet constitute an integrated framework which might perform the functions that good theory can do. Theory is sometimes seen as something of an irrelevant luxury, a kind of add-on. Yet theory is always present in our interactions with each other and the world: explicit theory is both better considered and more amenable to refutation than the invisible "common-sense» theories that we would otherwise operate with. Below I deploy theory specifically to assist in the development of an approach to the enhancement of teaching and learning in higher education based upon robust policy scholarship. Such a use of theory can help us to:

- Conceptualise current situations in clearer ways. It can provide better maps and explicit signs and symbols to populate them. 
- Identify potential mistakes, pitfalls and blind alleys in planning and implementing change. It can improve radar equipment.

- Distinguish between poor and better ways of conceiving of issues and the potentialities of different responses. It can enhance differentiation.

- Know more accurately what isn't working or won't work, and why. It can improve diagnosis.

- Make better guesses at potential outcomes of actions. It can help lead to better prescriptions.

\section{A sociology of teaching and learning}

What kinds of questions might such a sociological approach to teaching and learning address at this, the meso level? They might include, for example:

- The social dynamics of the classroom: why and how is it that classes develop a character of their own which has important consequences for the teaching and learning process?

- The social dynamics of non-classroom-based learning such as e-learning, action learning sets and community-based learning.

- The social dynamics of the staff group: what processes go on among staff teams which lead to recurrent practices and regular sets of attitudes and meanings related to the teaching and learning process?

- The interaction between social context and learning environment: what leads certain technologies to be adopted, adapted or ignored to different degrees in different social locales?

- The significance of semiotics: how do different «signs» (for example «the lecture», "the exam») come to acquire very different connotations and emotional responses in different social locales?

- The significance of micro-politics: how do subjectivities, power relations, conceptions of role and inter-personal dynamics manifest themselves and impinge on teaching and learning, on curriculum and assessment?

- The significance of organizational context: how does the institutional context, in its cultural and resource dimensions or others, impinge on the learning process?

- The significance of social context for subjectivities: this is Coffield's question, in the quote above.

In all of these areas of study the same underpinning broad question as identified above can remain in place: «how can the processes of teaching and learning be enhanced?». While it is true that sociologists rarely like to take questions like these from others, preferring (as Ozga, 2000, points out) to make their own questions, such a question is an important and challenging one.

Other possible ones do exist of course. They include: "why is it this way?»; "whose interests are being served here?»; "what else is going on other than teaching and learning of the manifest curriculum?»; «how else could this be 
done?». However, for the purposes of this paper we will retain that underpinning question about enhancement.

\section{Theoretical precursors}

Recent years have seen the development of two strands of theory, rooted in earlier social constructionist thinking and Marxist materialism respectively (Lave, 1993) which have the potential to provide a good base for a social theory of learning and teaching. These are the twin strands of communities of practice theory and activity systems theory. Combined we could term the general approach «social practice theory», or SPT.

Some key themes of SPT are:

- Activity (or practice): particularly as derived from Vygotsky, this concept implies social engagement with the world. An activity system consists of groups of individuals in distinct roles engaged in a common activity using mediating artefacts and operating on the basis of largely shared rules and conventions. The important characteristic is that the nature of the activity is not objectively discernible but is defined by the participants. Engagement on a research project is an example. The character of what the project means may appear to be objectively «given» but is actually socially constructed in the process of doing it. There are clear links in this with the work of Dewey and Mead in the USA.

- Communities of practice: a closely interacting group of practitioners within which contextualised, situated learning is always happening and is legitimized (Lave and Wenger, 1998). The research project team or teaching team may form a community of practice within a research centre or department. A single community of practice may incorporate a number of activity systems, depending on the number of distinct projects or activities they are engaged in, and a person may belong to a number of communities of practice.

- Identity: is not a fixed entity but a relational process and for this reason is sometimes referred to in terms of "subjectivity» (Prichard, 1999) or the self (Mead, 1913) though these terms carry subtle but important differences. Wenger (1998: 153) makes the point that we know who we are by what is familiar, understandable, usable and negotiable while we know who we are not by what is foreign, opaque, unwieldy and unproductive, that is by otherness. Personal and social identity is thus relational in character, involving simultaneously both a positive and negative positioning. Partly because of this identity or, better, identities, are not singular and fixed but multiple, dynamic and situationally contingent.

- Meaning: as distinguished from information (Baumard, 1999) is the product of learning. Meaning implies the way we understand the world and our place in it. It involves knowing about things, sometimes tacit knowing: the way they interconnect and the way we relate to them, including connotative 
codes that they carry. Thus for example higher education regulatory agencies such as the QAA and its procedures carry meaning for HE professionals over and above the information they have about such agencies. This meaning will vary from location to location to a greater or lesser extent.

- Discourse: language too is a form of social practice, one which is both conditioned by and conditions the social structures which give regularity and a certain degree of predictability to behaviour. Examples of such structures include educational ideologies, class structures and so on. While discursive repertoires are partly exogenous to a community of practice and imported into it, the social construction of reality within a community of practice also involves discursive creation, negotiation and contest as well as simple articulation. While some see Discourse as language and practices and discourse as language (practices) only, this distinction is not made here: language practices and social practices instantiate each other.

- Technology: the role of technology within social practice is not limited to the simple use of tools. The tools and techniques used for achieving ends are themselves bound up in constructivist social processes. The fact that photocopy machines and desktop computers were initially predicted to be irrelevant to office practice (Brown and Duguid, 1991) demonstrates the important interactions between technology and social practice. Within the existing (situated) practices at the time of their invention it was true that they were and would be redundant: it was difficult to envisage any alternative. However the introduction of technologies changes practice and so the nature of the constructed social world, as brief reflection on the use and effects of Microsoft Powerpoint and associated projection facilities and room layouts in universities will illustrate. At the same time social practice shapes the way technologies are defined and used within the large range of possibilities that they frequently present (Knight and Trowler, 2001, 49-50).

There are problems with these two strands of theory as they have been developed so far:

1. It seems impossible to define where the boundaries of «communities of practice» are, or even quite what communities of practice are. The best that Wenger $(1998,125-6)$ can do is demarcate their characteristics rather than define them. In fact more recent theory suggests that it is precisely the places where communities of practice interact that are the most interesting analytically (Engestrom, 2001).

2. While there is a rhetorical emphasis on the significance of conflict and communities of practice as sites of tension, in practice much of this literature stresses shared values and attitudes, sustained mutual relationships, shared ways of doing things together. This applies as much to activity systems theory as to communities of practice theory, despite the fact that the former has roots in Marxist conflict theory. 
3. There tends to be an emphasis on intersubjectivity in this literature; on mutual knowledge and shared sets of meanings such that conversation is easy and efficient. There is no need for introductory preambles and there is much jargon and many shortcuts to communication. This occludes the many instances of mal-communication, misinterpretation and unfounded assumptions which happen even in the most closely-bonded workgroup.

4. The appreciation of the operation of power within workgroups is largely rhetorical. However one defines power and whatever dimensions of its operation one focuses upon, it certainly is found in the operation of workgroups and does have a significant impact upon them. This is under-theorised and under-emphasised in much of the literature on communities of practice and activity systems so far.

5. There is an odd choice of practices used to illustrate and develop the theory. Thus Lave and Wenger (1991) use 5 studies of apprenticeship: Yucatec midwives; Vai and Gola tailors; naval quartermasters; meat cutters and nondrinking alcoholics. Lave (1988) studies apprentice tailors. Wenger (1998) similarly confines attention to the recherché: insurance claims processing. Gherardi et al. (1998) study construction site workers. Orr (1987) looks at photocopier technicians. There are exceptions, for example Brown, Collins and Duguid (1996) who do study teaching and learning of mathematics. But in such cases the level of empirical detail is usually very limited. So far there has been only patchy application of SPT to higher education contexts.

Despite these problems a social practice approach, properly developed, can form the basis of a sociological theory of teaching and learning in HE because it recognizes the significance of:

- The individual in context: takes into account both the figure and the ground.

- Social interaction at the meso level and the constructive processes there.

- Workgroups and teams as open, natural systems.

- The operation of both agency and structure.

- The interaction between tools, including learning technologies, and their social context.

- The inter-relationship between social interactions and individual subjectivities.

- The operation of power at the meso level.

\section{A sociology of enhancement}

However, as well as a sociology of teaching and learning, a sociology of enhancement of teaching and learning requires good theories of change. When these two literatures are combined the prospects for illuminative theory which can inform practice in really useful ways becomes a realistic possibility. 
There is of course a rich management literature on change and leadership. There is even a considerable literature on change and leadership in educational contexts, though largely to do with schools rather than higher education. Yet much of this educational leadership and change literature is under-theorised, or applies theory in rather undeveloped and inelegant ways.

The earlier work of Michael Fullan $(1993,1999)$ provides one example. While we may agree with many of his conclusions about change processes it seems clear that these are derived from experience rather than a fully worked theoretical framework (which itself, of course, might be partly derived from experience). His more recent work (2002) employs complexity theory to some extent, but not consistently, nor in a way which contributes a great deal to his earlier contribution.

Conversely where theory is extensively used to illuminate change processes it is sometimes deployed as a rather blunt instrument. This is the case with Kezar and Eckel (2002) who draw on a range of theories of culture in order to establish appropriate change strategies in the different cultural contexts of six different higher education institutions (HEIs). While this is a laudable attempt to establish the salience of change management approaches in a way which recognises the significance of contingent factors associated with culture, it falls down because of its poor theoretical base. The authors seek a «middle ground» (p. 436) between different theoretical approaches but what they succeed in doing is mixing incommensurable understandings of culture. One approach they draw on (Berquist's, 1992) seeks to categorize HEIs in one of 4 archetypal templates. In other words they adopt a nomothetic ontology by «naming» the institutional cultures of their case study HEIs; and they only have four names to play with — collegial; managerial; negotiating; developmental. Another (Tierney's, 1991) takes an altogether different perspective, seeing organizational culture as essentially unique in each case: it adopts an ideographic approach.

In practice Kezar and Eckel resolve this unrecognised paradox by adopting the former approach: focusing on the top team, on the significance of «founding fathers» and concentrating on management actions rather than how they were received or implemented. In adopting a unitary, closed theoretical approach to culture they miss the diversity of local level practices, attitudes and values on the ground that theoretical approaches such as Tierney's consider so important. Yet at a rhetorical level they recognise the significance of understanding «street level» practices and processes for being able to explain what works and what doesn't in a particular place and time. The theoretical lens they actually use is not fit for their purpose.

Theory used inappropriately or simply rhetorically can therefore be counterproductive in that it obscures rather than illuminates: as Shaw and Crompton (2003) put it; "theory, like mist on spectacles obscures vision». Others have raised a number of other objections regarding the deployment of theory in general, most notoriously Tooley and Darby (1998). Thomas (2002), also a theoretical sceptic, characterises educational research as being under «theory's spell», and a dangerous one. 
I disagree: theory properly used can illuminate: theory is the spectacles, not the mist on them. But (as those of us who are ageing know only too well) one needs the appropriate spectacles for different purposes. As the above discussion suggests, that theoretical perspectives need to be chosen and applied with care and discrimination. Ball $(1995,268)$ puts this well:

But will any theory do? I think not! We must consider how as well as why we employ theory. Theory can also work to provide comforting and apparently stable identities for beleaguered academics in an increasingly slippery world. Theory can also serve to conjure up anterior norms and lay its dead hand upon the creativity of the mind. Too often in educational studies theory becomes no more than a mantric reaffirmation of belief rather than a tool for exploration and for thinking otherwise. Such mantric uses of theory typically involve little more than a naming of spaces. This is what Dale (1992) calls «theory by numbers».

\section{Policies and practices}

Policies oriented to the enhancement of teaching and learning in higher education have been largely based on merely-tacit and not particularly good theories of teaching and learning and of change. Thus Skelton comments on the nowmuch-expanded National Teaching Fellowship scheme which rewards excellent higher education teachers with $£ 50,000$ and a short blaze of publicity:

No explicit model or strategy for educational change appears to inform the work of the 20 fellowship holders. Implicitly they are viewed as reflective practitioners who will disseminate «good practice» within the sector. This approach appears to be based on «transfer» theories of learning which do not recognise the complexity of educational change [...] Transfer theories of learning fail to recognise the complexity involved in educational change and the difficulty of «embedding good practice». It has been demonstrated that «ordinary» teachers will not accept and apply curriculum changes unless they share the educational beliefs and values that underpin them. (Skelton, 2002, 3 and 11)

Often there is considerable reliance on the development of enhanced reflectivity among practitioners, sometimes with a view to developing a critical mass of them in universities so that these become "learning organizations». From this perspective change involves better approaches to practice eventually being dispersed by individuals across organizations and systems. Such an approach appears to be endemic to formal educational policy-making in the UK as both Coffield (2002) and Guest (2001) argue in relation to vocational education and training policy where a flood of short-term and disparate initiatives focused largely on the individual lead to...

[...] behaviour that is unlikely to tackle the underlying problem at an organizational level and leaves the cultural institutions that gave rise to the problem in the first place largely untouched. (Guest, 2001, 5) 
In the British higher education context this problem continues to plague teaching and learning issues. For example, the 2003 White Paper The Future of Higher Education sets the scene for newly recruited academics to meet certain minimum teaching standards. This is however unlikely to raise standards of teaching and learning because it takes no account of the very significant influence upon their professional practice of the contexts which they are entering.

\section{Teaching and Learning Regimes and the Enhancement of Practices}

In some of my recent writing I have attempted to address these lacunae by:

a) using the insights of social practice theory to develop an approach to the sociology of teaching and learning and

b) apply that approach to the question of enhancement of teaching and learning, developing an improved theoretical and conceptual understanding in that area too.

In this I have tended to eschew the broader underpinning sociological questions which are possible, outlined above. Preferring to «keep it simple, stupid» I have confined my attention to the fundamental question already identified as being the most significant one for many other writers: «how can the processes of teaching and learning be enhanced?».

The concept of teaching and learning regimes (TLRs), developed and elaborated in earlier papers (Trowler and Cooper, 2002; Trowler, 2003; Trowler, Fanghanel and Wareham, 2005), grows out of SPT. It develops some of the insights discussed above in relation to the dimensions of cultures and subjectivities in universities which relate both to teaching and learning and to change processes there.

TLRs involve a constellation of nine cultural components or «moments» (a concept adapted from Harvey, 1996) of the social process which are interlaced with social practice. Behaviour is only one of the significant dimensions of social life as it operates at the meso level, albeit the one most amenable to empirical research. Social processes flow through and around these moments, and they need to be understood as operating simultaneously and holistically rather than individually or in a disaggregated way. They are separated and described individually here for the purposes of clarity only.

These moments are:

- The development and attribution of meanings. As the workgroup engages on its project, the meaning of that project itself gains ontological solidity and the components which compose the project also develop a particular reality. Thus an undergraduate programme in a particular department comes to be thought about in unique ways and, for example, the meaning of the grading criteria, that of the grades themselves are collectively generated and communicated over time, becoming «solidified» in the process. 
- The development and attribution of codes of signification. Activities, organizations, terms, concepts and things not only have meanings attributed to them in a cognitive sense but are layered with affective (emotional) significance. Thus the term "quality», and organizations and people associated with it in a particular university may evoke responses of delight, fear, worry, stress, or something else. Such responses are not simply individual in nature - they are socially conditioned as workgroups meet new circumstances, discuss them and respond to them. The layers of emotion and meaning encapsulated in the phrase "codes of signification" are cultural in origin and import - both in terms of Great Culture and in local, workgroup cultures. These are very significant aspects of TLRs because concepts and practices like «lectures», "multiple-choice examinations», "problem-based learning» and others become heavily loaded and so evoke a response in terms of emotion and connotations. Any innovation will elicit responses of this sort - and that in itself will condition subsequent actions.

- The development and use of discursive repertoires. Discourse too is socially generated and used. It both limits and enables thought and actions, structuring the way projects and tasks are conceived, discussed and pursued. While discursive repertoires, the words and phrases used to express ideas, are generated in the wider society they are also locally generated, especially when they refer to forms of knowing related to the workgroup's project specifically. Local discursive repertoires may favour the conceptualisation of teaching and learning as involving a constructivist process, for example, and so shape the practices in a department or workgroup. «New Higher Education discourse», derived as it is from fiscal discourse, tends to commodify knowledge, to describe teaching as involving "delivery of content» and to commercialise higher education practice. In so doing it can involve shaping the way in which professional practice is conceived towards these ways of thought (Trowler, 2001).

- The development of recurrent practices. As workgroups engage in tasks over time they develop ways of doing things which become «just natural» — «the way we do things around here». These are taken for granted and so are only rarely reflected on or evaluated. They include specific ways of and circumstances for using tools, such as email communication for example, and ways of behaving in meetings or with students. It is usually only new entrants to the workgroup who find these practices unusual or surprising and, after a year or so, often sink into recurrently practising them themselves. They do, however, come to be questioned by other outsiders, such as quality assurance agencies or even quality assurance processes involving academics from other departments in the institution.

- The formation of subjectivities in interaction. TLRs are socially created but they comprise a number of individuals whose individuality is not lost within them. As people interact within the workgroup a process of «hammering» is occurring so that personal and professional identities (or sub- 
jectivities) are negotiated, sustained, attacked, defended and so on. This can be significant for teaching, learning and assessment practices where dimensions of identity impinge on these areas of practice: the professor who defends academic integrity to his dying breath even at the cost of confusing students; the "student fundamentalist» whose identity is bound up with the perceived interests of students; the researcher who sees discussion of teaching as intellectually demeaning, and so on.

- The development and sustenance of power relations. All social groups involve the transmission and application of power of various sorts: from simple brute making people do things which they do not want to do to more subtle agenda-setting or circumstance-changing practices. The shape that power takes, the way it flows and how it surfaces will vary from regime to regime. One thing is constant, though, power relations are always present, and they always have an effect on the practices of workgroups, including those to do with teaching, learning and assessment.

- The generation of tacit assumptions. All workgroups, in fact everyone in society, operate partly on the basis of tacit assumptions. Not to do so would simply be impracticable. Such assumptions are not surfaced, in fact some forms of knowing cannot be surfaced directly. In TLRs collective assumptions about, for example, assessment practices, their role and value, can influence the practices in that area in very significant ways. These assumptions may have no basis in evidence, may be detrimental to good practice and may even result in practices which are more effortful and less effective than many others, yet they continue to exercise their baleful influence.

- The development and use of rules of appropriateness. Associated with several of the above characteristics, these are understandings developed within a workgroup about the kinds of behaviours which are, and are not, appropriate. How a teacher behaves in the classroom, the kinds of interactions he or she has with students, the level of work she or he allocates to students, whether and how textbooks are used, and the rest. Rules of appropriateness developed in a TLR condition what feels normal and what feels deviant in relation to teaching, learning and assessment. They are often codified in, for example, student handbooks.

- The development and application of implicit theories. Again, these are integral to some of the above characteristics, particularly the tacit assumptions within a TLR. Implicit theories are, in a sense «bigger» than assumptions though. They encompass, for example, theories about teaching and learning - constructivist versus transmissive, for example (Burgoyne and Stuart, 1977; Marton and Saljo, 1976; Saljo, 1979; Entwistle and Ramsden, 1983; Gow and Kember, 1993; Kugel, 1993)— which come to inform practice. They are more likely to be surfaced from time to time than tacit assumptions are, partly because they relate to practice in a more direct way, and partly simply because they are «bigger» and so there is more likelihood that at least in part they will be made explicit. These implicit theories are not always generated wholly or mainly within the 
workgroup. They may come from pre-service or in-service training courses or may result from disciplinary socialization, for example. Wherever their origin, their impact on the practices of the workgroup are nonetheless significant. Thus transmissive theories of learning will guide the architect's thinking about the design of teaching spaces in universities. And of course it will condition the lecturer's planning of sessions and their conduct of them, so that the lecture mode predominates and little space is created for students to play with and use ideas, to practice new language, to apply and synthesize knowledge or to explore the impact of new ideas upon old learning.

Essentially what is happening as these TLRs are constructed and enacted is the working out of one dimension of "culture». Generally speaking that is a word for the lazy (as Gerth and Mills, 1970, remind us), and so it is helpful I believe to deconstruct it into component moments in this way. However, a general definition of culture I would like to offer is:

The complex of taken-for-granted values, attitudes and ways of seeing and relating which are articulated through and reinforced by recurrent practices in a given context. Ways of thinking, feeling and of behaving are both constructed and enacted in local contexts.

This definition gives a deliberately static flavour to culture, one largely of mutually-reinforcing stasis between ways of thinking, feeling and acting. This reflects the nature of cultures - they are quite stable. But of course they do change too. With regard to changes in TLRs, such change may be initiated from within or without: from an enthusiastic innovator with a good idea or from some new policy initiative from institutional management or higher up: the government or one of its QUANGOs, for example. And of course change may just happen organically, an unintended and unpredicted outcome of the mix of developments happening around and permeating a particular cultural locale. The significant contribution that the study of TLRs can offer to our understanding (and the practice of) change is the fact that they act as «filters», conditioning the reception and implementation of change, as well as generating their own changes or acting as a brake on it.

\section{Implications for enhancement}

It seems clear that a social practice perspective militates against any simple model of «evidence-based practice» when considering actions oriented to enhancing teaching and learning in higher education. An evidence-based practice approach would seek to establish, through careful research, the "best» approaches teaching and learning. It would then disseminate them across the higher education landscape. However a social practice approach suggests that, because of very different histories and contexts, different cultural milieux and therefore different TLRs, what is «best» for one place will be sub-optimal else- 
where. Moreover these variables will also influence in important ways the reception and implementation locally of initiatives to enhance teaching and learning, often in ways that are quite difficult to predict.

Thus change initiatives oriented to enhancement of teaching and learning in higher education need to be approached through policy scholarship rather than policy science. Policy science adopts a "scientific» standpoint in order to develop technical-rational, top-down prescriptions for action. Policy scholarship, by contrast, locates an understanding of educational policy and change in the context of cultural and ideological differences and struggles which are both situationally specific and dynamic. The following section unpacks some of the implications of taking this kind of approach. I have segregated them into categories which concern:

- how enhancement initiatives are generated;

- how proposals for change are «read»;

- how they are implemented;

— and what the outcomes are likely to be.

\section{The genesis of enhancement initiatives}

- Existing cultures, including TLRs, are extremely tenacious: cultural sensitivity is very important in devising change strategies. This makes the transfer of innovation hard because proposals for change touch on, for example, existing recurrent practices, on codes of signification and on power and identity relationships. The different types of ground they fall on are likely to be fertile or hostile in various degrees. It is hard to try to take this into account during the planning process. Those involved in planning change will often lose sight of the detail of constraints and issues on the ground, even if they are practitioners themselves. The planning process itself imposes blinkers on the vision of the planners because of the generalising bias of planning itself. However, when planners think separately and creatively about the issues above and below it can help smooth the implementation process.

- While we often talk about «change» in the singular, most innovations actually involve multiple changes. They often also come wrapped up in a policy «bundle». These are rarely internally coherent. Again, planners need to consider the full range of innovations and policies, even when looking at the detail of the one in front of them. What to planners and policy-makers at the top level of the change process may be a carefully crafted and beautiful artifact (let's say a lovely pot), when it hits those on the ground in HE institutions it may look like a pile of broken pieces. Thinking about policy making without thinking about policy reception and implementation usually means that the policy "pot» is simply thrown from the roof. The results are all-too predictable. While of course planners cannot know everything about, or predict, policy reception and implementation in the myriad con- 
texts where policy will hit, nor the detailed configurations of different TLRs, they can engage in thinking "outside the box" of their own perspective and situation. They can also consult, pilot and open channels for continuous feedback. Too often however these simple steps are not taken, or are addressed at an only-rhetorical level.

\section{Reception ("reading») of proposals for change}

- Responses to change on the ground will be strongly influenced by the different TLRs that exist there, including their different histories. We can therefore expect the same intentions to work out quite differently in different contexts as TLRs filter and refract policies.

- Innovations come loaded with multiple potential meanings and can emotional responses - though these are not necessarily evoked, or evoked as expected, when the innovations hit the ground. Innovations may be welcomed warmly or viewed with suspicion or as a threat depending upon pre-existing codes of signification in particular. Sometimes predicting responses is extremely difficult, but it is worth the effort to try and make educated guesses about the probabilities of different sorts of outcome emerging.

\section{"Implementation» of change: adopt or adapt?}

- Changes threaten to disrupt the distribution of power in HE contexts, including the relations between teachers and students (depending on the nature of the innovation). Expect opposition from «losers».

- Mandated changes may produce compliance where sanctions are in place, but professionals within TLRs have considerable scope for compliancewithout-change, resistance and subversion. Changes are often «bent» to be congruent with pre-existing ways of thinking, feeling and acting.

- Successful change, like successful learning, is a constructive process: the meaning and character of an initiative will develop and attain more substance as it is «implemented». It develops locally-imbued meaning and the practices associated with it will be different in different places.

\section{Outcomes of change initiatives}

- Innovations have a greater chance of success if they are seen as profitable (in a broad sense) by professionals in the areas that matter to them —or that are made to matter to them. Congruence with sets of interests within TLRs can lead to successful implementation.

- Expect different outcomes to the «same» initiative in different places: the different pre-existing situations, histories and configuration of the moments outlined above will lead to differences in reception and implementation. 
- Initiatives will change their context as well as being changed by their context: TLRs are open, natural systems. Changing technologies, for example will change practices and ways of interacting.

\section{A final comment}

Cultures are extremely tenacious both at a national, macro level and at the meso level. Inertia is incredibly strong in educational settings, Joe Farrell at the Ontario Institute for Studies of Education makes this point in commenting in relation to the myriad educational initiatives which have rolled across North America over the decades, many of them heralded as bringing a new educational revolution with them. Almost all have disappeared without a trace. Returning to the school at which he was a young teacher 30 years previously, Farrell is able to recount just how little has changed in the school environment or its practices (Farrell, 2000).

Bascia and Hargreaves $(2000,20)$ agree:

[...] educational policymakers have not learned anything from these decades of research, whose recurring theme has been the complexity (if not outright failure) of educational change and the inadequacy of so many reform ideas... we have so little evidence that anyone has learned anything new about the processes of teaching and schooling beyond the confines of their own personal locations.

Great expectations in higher educational reform are so often followed by mixed performance (to steal another book title: Cerych and Sabatier, 1986). My analysis of the dimensions of culture as these related to teaching and learning has helped to show why this is the case.

However, by developing good social theory which relates to both teaching and learning on the one hand and change processes on the other we can come see the world in particular ways and to make connections in what we observe that would not otherwise be made. Theory gives us a radar and improved diagnostic and prescriptive tools. It helps us predict how things may go as well as helping us to understand and make decisions about circumstances so that outcomes are more often ameliorative and enhancing than deleterious or simply disappointing. The development of better social theories of learning and teaching can help re-balance the emphasis to date on theories that come from a psychological level of analysis. Combined with good theories of change, these have considerable potential to improve practice in the enhancement of teaching and learning in higher education. Finally, at a personal level for those leading change, a well-developed theoretical perspective on professional practice can one see what might otherwise be emotionally draining and harmful interactions as manifestations at the personal level of broader forces at work. Seen in this way their harmful personal effects are mitigated, leaving the more beneficial interactions to be appreciated in their own right. 


\section{References}

BALL, S.J. (1995). «Intellectuals or Technicians? The urgent role of theory in educational studies». British Journal of Educational Studies, 43, 255-271.

Bascia, N.; Hargreaves, A. (eds.) (2000). The Sharp Edge of Educational Change. London \& New York: Falmer Press.

Baumard, P. (1999). Tacit Knowledge in Organizations. London: Sage Publications. BerQuist, W.H. (1992). The Four Cultures of the Academy. San Francisco: Jossey Bass BIGGS, J. (1999). Teaching for Quality Learning at University. Buckingham: Open University Press/SRHE.

BRown, J.S.; Duguid, P. (1991). "Organizational Learning and Communities of Practice: toward a unified view of working, learning and innovating». Organization Science, 2(1): 40-57.

Brown, S.J.; Collins, A.; Duguid, P. (1996). «Situated Cognition and the Culture of Learning». In MCLellan, H. (ed.). Situated Learning Perspectives. Englewood Cliffs, NJ: Educational Technology Publications, p. 19-44. [First published as: Brown, J.S.; Collins, A.; Duguid, S. (1989). «Situated Cognition and the Culture of Learning». Educational Researcher, 18(1), 32-42.]

Burgoyne, J.; STUART, R. (1977). «Implicit Learning Theories as Determinants of the Effect of Management Development Programmes». Personnel Review, 6 (2), 5-14. Cerych, L.; SABATIER, P. (1986). Great Expectations and Mixed Performance. London: Trentham.

COFFIELD, F. (1999). «Breaking the consensus: Lifelong learning as social control». British Educational Research Journal, 25(4): 479-499.

DALE, R. (1992). «Recovering from a Pyrrhic Victory?». In ARNOT, M.; BARTON, L. (1992). Voicing Concerns: sociological perspectives on contemporary education reforms. Wallingford, Oxfordshire: Triangle.

DePaRTMENT FOr EdUCATION AND SKILls (2003). The Future of Higher Education. London: HMSO

ENGESTROM, Y. (2001). «Expansive Learning at Work: toward an activity theory reconceptualization». Journal of Education and Work, 14, 1, 133-156.

ENTWISTLE, N.; RAMSDEN, P. (1983). Understanding Student Learning. London: Croom Helm.

FARRELL, J.P. (2000). «Why is educational reform so difficult?». Curriculum Inquiry, 30(1), 83-103.

Fullan, M. (1993). Change Forces. London: Falmer.

- (1999). Change Forces: The sequel. London: Falmer.

- (2002). Change Forces With a Vengeance. London: Routledge Falmer.

GerTH, H.H.; Mills, C.W. (eds.) (1970). From Max Weber: essays in sociology. London: Routledge (first published 1948).

Gherardi, S.; Nicolini, D.; Odella, F. (1998). «Towards a Social Understanding of How People Learn in Organizations: the notion of situated curriculum». Management Learning Journal, 29(3): 273-297.

Gow, L.; Kember, D. (1993). "Conceptions of Teaching and Their Relationship to Student Learning». British Journal of Educational Psychology, 63, 20-33.

GUEST, D. (2001). Motivation for Workforce Development: the role of national culture. London: Performance and Innovation Unit.

Halsey, A.H.; LAuder, H.; Brown, P.; Wells, A.S. (eds.) (1997). Education: Culture, Economy, Society. Oxford: Oxford University Press. 
Haralambos, M.; Holborn, M. (2004). Sociology: Themes and Perspectives. London: HarperCollins ( $6^{\text {th }}$ edition).

HarveY, D. (1996). Justice, Nature and the Geography of Difference. Oxford: Blackwell. Hativa, N.; GoOdyear, P. (2002). Teacher Thinking, Beliefs and Knowledge in Higher Education. Dordrecht: Kluwer.

KeZAR, A.; EcKeL, P.D. (2002). "The Effect of Institutional Culture on Change Strategies in Higher Education». The Journal of Higher Education, 73, 4, 435-460.

KNIGHT, P.; Trowler, P. (2001). Departmental Leadership in Higher Education: new directions for communities of practice. Buckingham: Open University Press.

Kuget, P. (1993). «How Professors Develop as Teachers». Studies in Higher Education, 18, 3 315-328. Last accessed 8.3.04.

LaVE, J. (1988). Cognition in Practice: Mind, mathematics and culture in everyday life. Cambridge: Cambridge University Press.

- (1993). "The Practice of Learning». In Chaiklin, S.; LaVe, J. (eds.) (1993). Understanding Practice. Cambridge: Cambridge University Press: 3-32.

Lave, J.; Wenger, E. (1991). Situated Learning: Legitimate Peripheral Participation. Cambridge: Cambridge University Press.

Marton, F.; SALJO, R. (1976). «On Qualitative Differences in Learning 1. Outcome and Process». British Journal of Educational Psychology. 46, 4-11.

Mead, G.H. (1913). "The Social Self». Journal of Philosophy, Psychology and Scientific Methods, 10: 374-380.

OrR, J. (1987). Talking about Machines. (SSL Report) Palo Alto, CA: Xerox Palo Alto Research Centre.

OzGA, J. (2000). Policy Research in Educational Settings: contested terrain. Buckingham: Open University Press.

PRICHARD, C. (1999). Identity Work - moving the "theory of the subject» from "division» to «depth» in critical organizational analysis. Paper for the Critical Management Studies Conference, Manchester School of Management, UMIST, July.

SALJO, R. (1979). Learning in the Learner's Perspective: 1 - some commonsense conceptions. Reports from the Institute of Education, University of Gothenburg, no. 77.

Shaw, I.; CrOmpton, A. (2003). «Theory. Like Mist on Spectacles, Obscures Vision». Evaluation, 9, 2, 192-204.

SKELTON, A. (2002). Understanding "Teaching Excellence» in Higher Education: a critical evaluation of the National Teaching Fellowship Scheme. Final Report to the ESRC, July.

THOMAS. G. (2002). «Theory's Spell: on qualitative inquiry and educational research». British Educatonal Research Journal, 28, 3, 419-434.

TierneY, W. (1991). «Organizational Culture in Higher Education: Defining the essentials». In PETERSON, M. (ed.). ASHE Reader on Organization and Governance. Needham Heights, MA: Ginn Press, p. 126-139.

Tight, M. (2003). Researching Higher Education. Buckingham: Open University Press/SRHE.

TOOLEY, J.; DARBY, D. (1998). Educational Research: a critique. London: OFSTED.

Trigwell, K. (2000). Phenomenography: Discernment and Variation. www.lear ning.ox.ac.uk/iaul/Phenom_ISL_paper.pdf. Last accessed 27.4.04.

Trowler, P. (2003). Veranderingen in Het Hoger Onderwijs in Theorie en Praktijk (Change in Higher Education in Theory and Practice). In DrUINE, N.; Clement, M.; WaeYTENS, K. (eds.). Dynamiek in Het Hoger Onderwijs. Leuven: Leuven University Press, p. 15-30. 
Trowler, P.; CoOper, A. (2002). «Teaching and Learning Regimes: implicit theories and recurrent practices in the enhancement of teaching and learning through educational development programmes». Higher Education Research and Development, $21,3,221-240$.

Trowler, P.; Fanghanel, J.; Wareham, T. (2005). «Freeing the Chi of Change: The Higher Education Academy and Enhancing Teaching and Learning in Higher Education". Studies in Higher Education, 30, 5, 427-444.

WeNGER, E. (1998). Communities of Practice: learning, meaning and identity. Cambridge: Cambridge University Press.

WhitTy, G. (2002). Making Sense of Education Policy. London: PCP. 